\title{
Ciudadanos entre estado e imperio
}

\author{
BJÖRN HAMMAR*
}

Artículo recibido: $1^{\circ}$ de octubre de 2014

Artículo aprobado: 15 de abril de 2015

Doi: dx.doi.org/10.12804/desafios27.2.2015.04

Para citar este artículo: Hammar, B. (2015). Ciudadanos entre estado e imperio. Desafíos, 27(II), 145-165. Doi: dx.doi.org/10.12804/desafios27.2.2015.04

\section{Resumen}

El mundo interno está estrechamente vinculado con la forma de concebir los nexos entre el ciudadano y el poder público. Aspectos que en el pensamiento político moderno frecuentemente han sido atribuidos a un orden externo, relacionado con el Estado soberano, pueden, no obstante, situarse en el fuero interno de los ciudadanos. Problemas vinculados con la fundación del orden político, tales como el temor, la inseguridad y la divergencia, no únicamente provienen de fuerzas externas situadas en el exterior del ciudadano, sino también de su mundo interno, lo cual significa que la contingencia política abarca ese mundo. Thomas Hobbes vuelve una y otra vez sobre la necesidad de controlar o minimizar la contingencia del fuero interno en el marco del Estado soberano. El presente articulo pretende, sin embargo, ampliar las perspectivas que en el pensamiento político moderno han sido dominadas por la soberanía estatal, al inquirir sobre cómo el mundo interno es concebido en relación con la tensión entre Estado (o república) e imperio como la fundación del orden político. La coexistencia bistórica y teórica de Estados e imperios no necesariamente ha sido antagónica o de exclusión mutua, como frecuentemente ha sostenido el republicanismo moderno. Si el nexo entre república e imperio constituye una parte inherente del orden político,

* Profesor titular de Ciencia Política de la Universidad de Örebro (Suecia). Correo electrónico: bjorn.hammar@oru.se 
quedan por tratar cuestiones sobre cómo ese nexo está relacionado con el mundo interno del ciudadano. La forma en que se define el ciudadano y su self en relación con Estados e imperios modernos se nutre de y tiene consecuencias para concepciones de territorialidad, gobierno y soberanía.

Palabras clave: Estado, imperio, territorialidad, soberanía, ciudadano, voluntad, memoria, mundo interno.

\title{
Citizens between State and Empire
}

\begin{abstract}
The internal world is closely related to how the bonds between the citizens and public power are conceived. Aspects that in modern political thought often have been attributed to an external order associated with the sovereign state can nonetheless be located in the internal world of the citizen. Problems associated with the foundations of political order, such as fear, insecurity and divergence, do not only stem from external forces located outside of the citizen, but also from her internal world, which means that political contingency comprises that world. Thomas Hobbes returns once and again to the need to control or minimize the contingency of the internal world within the sovereign state. This paper seeks to widen the perspective dominated by sovereign statehood in modern political thought, by inquiring how the internal world is conceived in relation to the tension between state (or republic) and empire as the foundation of political order. The historical and theoretical co-existence of states and empires has not necessarily been contentious or of mutual exclusion, as modern republicanism frequently claims. If the link between republic and empire is an intrinsic part of political order, questions remain to be addressed about how this link is related to the inner world of the citizen. How the citizen and herself is defined in relation to modern states and empires both feed upon and have consequences for conceptions about territoriality, government and sovereignty.
\end{abstract}

Keywords: state, empire, territoriality, sovereignty, citizen, will, memory, internal world. 


\title{
Cidadãos entre Estado e império
}

\begin{abstract}
Resumo
O mundo interno está estreitamente vinculado com a forma de conceber os vínculos entre o cidadão e o poder público. Aspectos que no pensamento político moderno frequentemente têm sido atribuidos a uma ordem externa, relacionada com o Estado soberano, podem, contudo, situar-se no foro interno dos cidadãos. Problemas vinculados com a fundação da ordem política, tais como o temor, a insegurança e a divergência, não unicamente provêm de forças externas situadas no exterior do cidadão, mas também de seu mundo interno, o que significa que a contingência politica abarca esse mundo. Thomas Hobbes volta uma e outra vez sobre a necessidade de controlar ou minimizar a contingência do foro interno no marco do Estado soberano. O presente artigo pretende, no entanto, ampliar as perspectivas que no pensamento politico moderno têm sido dominadas pela soberania estatal, ao inquirir sobre como o mundo interno é concebido em relação com a tensão entre Estado (ou república) e império como a fundação da ordem política. A coexistência histórica e teórica de Estados e impérios não necessariamente tem sido antagónica ou de exclusão mútua, como frequentemente tem sustentado o republicanismo moderno. Se o nexo entre república e império constitui uma parte inerente da ordem política, ficam por tratar questões sobre como esse nexo está relacionado com o mundo interno do cidadão. A forma em que se define o cidadão e seu self em relação com Estados e impérios modernos nutre-se de e tem consequências para concepşões de territorialidade, governo e soberania.
\end{abstract}

Palavras-chave: Estado, império, territorialidade, soberania, cidadão, vontade, memória, mundo interno.

\section{Soberanía, geometría y territorio}

Para hablar de la política y del ciudadano, nos referimos frecuentemente a entidades de unas dimensiones inabarcables, siendo el Estado soberano sin duda uno de esos objetos tan inmensos que difícilmente podemos divisarlos. A pesar de —o gracias a — ser tan inabarcable, el Estado soberano ha llegado a ocupar un lugar omnipresente para la política durante varios siglos, independientemente de qué características y qué funciones se le haya atribuido desde diferentes perspectivas teóricas o posiciones ideológicas. 
Esa persistencia y omnipresencia del Estado la observamos con facilidad en la historia y práctica de la ciencia política, por ejemplo, en los debates que hace unas décadas se posicionaban sobre la presencia o desaparición del Estado en la disciplina. Dichos debates no versaban realmente sobre la ausencia o presencia del Estado, sino sobre qué papel debería de jugar este en los esquemas explicativos de la ciencia política. Y el Estado soberano estaba sin duda presente en todos esos esquemas, tanto en las perspectivas que proclamaban su ausencia como en las que buscaban su reaparición. Las primeras concebían el Estado soberano como un espacio dado para la vida política, mientras que las segundas lo identificaban como un sujeto unitario dotado de una voluntad autónoma.

Estos debates politológicos son solo un ejemplo reciente, pero sirven para poner de relieve dos de las características que desde la temprana Edad Moderna han ido vinculándose con el Estado soberano: geometría y voluntad. El Estado soberano se ha concebido como un espacio geométrico, algo que podemos ver reflejado en la imagen de unas fronteras territoriales, como la delimitación de entidades políticas mutuamente excluyentes. Esa exclusividad mutua no solo se refiere a la descripción visual de los mapas políticos, sino que significa establecer y reforzar la idea de que el dominio de un Estado termina donde otro empieza, al igual que todos los elementos que se vayan identificando con ese Estado en diferentes contextos (por ejemplo, territorio, ciudadanos, autonomía, seguridad, intereses, comunidad, legalidad, participación).

La esfera política entendida de forma geométrica supone que un ciudadano pertenece a uno u otro espacio político, al igual que la física determina que un cuerpo no puede estar en dos lugares al mismo tiempo. La identidad, la pertenencia y la participación quedan desde este punto de vista delimitadas por unas fronteras unívocas. Lo público y la vida ciudadana se describen, como consecuencia de esa exclusividad mutua y territorial, a través de los mapas de superficies planas y líneas nítidas. 
Paralelamente al surgimiento del Estado soberano durante la temprana Edad Moderna, la cartografía experimentaba transformaciones importantes y adquiría nuevos significados para el espacio político y el gobierno de las personas. ${ }^{1}$ Del mismo modo en que los mapas paulatinamente irían abarcando el globo en su totalidad dejando cada vez menos puntos ciegos, el Estado iría cubriendo el mundo dejando cada vez menos territorios y personas fuera de su dominio. Al igual que el Estado soberano pretendía ejercer un control exclusivo sobre su interior a través del territorio y la soberanía (Elden, 2013, pp. 279 y ss.), esa forma geométrica de organizar lo político iba extendiéndose desde Europa hacia otros continentes. La consecuencia de esa expansión ha sido que prácticamente la totalidad de las zonas pobladas del mundo están cubiertas por Estados (aunque bien es cierto que los océanos y algunos territorios con apenas población pueden ser problemáticos para la noción de exclusividad estatal sobre el espacio político). En la actualidad, se da por supuesto que todos vivimos en Estados.

La concepción geométrica del espacio público ha supuesto para el Estado soberano la búsqueda de unos límites unívocos entre una esfera política interior y otra exterior, esferas que son retratadas como concepciones muy distintas de la política. El interior del Estado soberano ha representado la posibilidad de orden, paz, justicia, legitimidad, legalidad, comunidad y participación, mientras que su exterior está constantemente expuesto a las contingencias del desorden, la guerra, la injusticia, la fuerza bruta, lo alegal y lo desconocido. ${ }^{2} \mathrm{Si}$ se considera que los Estados soberanos agotan el espacio político y que estos son mutuamente excluyentes, no es de extrañar que lo que queda fuera del Estado se defina como la ausencia de las propiedades políticas situadas en su interior. Esta división estricta entre interior y exterior del Estado además ha supuesto un divorcio de la labor académica, según la cual campos como las relaciones internacionales y la teoría política han tenido muy poco que decir el uno al otro.

\footnotetext{
1 Ver, por ejemplo, Benton (2010), Elden (2013), Laxton (2001) y Olsson (2007).

2 Sobre el nexo entre teoría política y relaciones internacionales en este sentido, ver Hammar (2001, pp. 75-113).
} 
Podemos empero observar cómo algunas de las dimensiones de esa separación entre interior y exterior, vinculada al Estado soberano, han sido objeto de estudio en disciplinas como las relaciones internacionales durante las últimas décadas. ${ }^{3}$ En este campo, han surgido perspectivas que cuestionan unas concepciones que no solo definen el Estado cómo el único sujeto con un poder real capaz de actuar y generar explicaciones acerca de lo que ocurre en la política mundial, sino que además dota al ente soberano de una voluntad autónoma, en torno a la cual se formulan nociones de identidades e intereses unitarios y dados.

Para algunos investigadores, los enfoques tradicionales de las relaciones internacionales han quedado obsoletos y anacrónicos por no haberse adaptado a unas transformaciones aceleradas que han afectado profundamente al funcionamiento de los Estados y al sistema internacional. Los argumentos de este tipo indican fenómenos globalizadores relativamente recientes como los principales causantes de una importante anacronía teórica en la disciplina. Es decir, afirman que los nuevos procesos de transnacionalización o globalización (política, económica, social, cultural, tecnológica, militar, etc.) requieren nuevas formas de entender las categorías políticas utilizadas en las relaciones internacionales.

Para otros, existe una debilidad inherente al corpus teórico-político de las relaciones internacionales. Sostienen que esta debilidad ha supuesto una falta de estudio profundo y riguroso sobre los fundamentos conceptuales de la disciplina. Desde esta perspectiva, la carencia teórico-política en el estudio de las relaciones internacionales no se debe principalmente a transformaciones aceleradas en su campo empírico, sino a que la disciplina carece desde el principio de disquisiciones penetrantes y rigurosas sobre la naturaleza de lo político. En este contexto, se señalan los puntos ciegos teóricos y ontológicos presentes en la forma de concebir las relaciones internacionales,

3 Para unos ejemplos recientes, ver Armitage (2013), Bartelson (2009) y Boucher (2009). 
argumentando que esta disciplina no ha inquirido suficientemente sus propios postulados sobre la política, el Estado y el ciudadano.

A pesar de despertar cierto interés en la teoría de las relaciones internacionales las limitaciones del Estado soberano como fundamento último de la vida política, hay aspectos relacionados con el espacio público, el ciudadano y el orden político que no suelen ser objeto de estudio en ese campo. La relación entre el mundo interno y la res publica es uno de esos puntos ciegos y el nexo entre Estado, ciudadanos e imperio es otro.

\section{Contingencia y transparencia del ciudadano}

La imagen del Estado como territorio y geometría va unida a la noción de la soberanía como voluntad. Se trata de una voluntad que expresaría los intereses e identidades propias de cada uno de los Estados que constituyen los fundamentos del sistema internacional. En ese universo inter-estatal, la política parece reducirse a voluntad cuyo fin último es generar cada vez más poder y autonomía. ${ }^{4}$ Esa generación de autonomía como fuente inagotable de la acción está relacionada con la ilusión de eliminar la contingencia a la que está expuesta la vida de los ciudadanos. A pesar del afán por fundar una voluntad soberana que, a través de la decisión y lo ejecutivo, elimine las incertidumbres y lo imprevisto de la vida pública, la contingencia sigue presente por muy soberana que se declare la acción del Estado y por muy nítidas que estén trazadas sus fronteras en los mapas. Pese a identificar el Estado con la eliminación de la contingencia de lo público, mediante territorios mutuamente excluyentes o de la voluntad del soberano como garante del orden, siguen condicionando la vida del ciudadano aspectos como la inseguridad, la incertidumbre, lo inesperado y lo incontrolable.

Si sobre el exterior del Estado soberano se ha proyectado un mundo ingobernable, en su interior la idea de controlar las contingencias de 4 Sobre la voluntad de poder como motor inagotable de la subjetividad en la modernidad,
ver Serrano Marín (2010). 
la vida pública ha sido muy importante. Gobernar el vínculo entre el mundo interno del ciudadano y el orden político ha sido clave para muchas concepciones de la res publica moderna. Para controlar la contingencia del mundo interno en el Estado soberano, ha sido frecuente vedarla, ignorarla o desplazarla a campos que no guardan una relación directa con lo público. Es empero difícil negar completamente la presencia de ese mundo interno cuando inquirimos sobre las diferentes dimensiones de la vida del ciudadano.

El ciudadano no suele ser descrito como un cuerpo político inabarcable en el mismo sentido que el Estado, pero se define constantemente en relación con entes públicos más abstractos, trascendentes y unitarios (por ejemplo, pueblo, nación y soberanía). Podemos apreciar cómo los espacios geométricos y la voluntad autónoma también han constituido nociones centrales para describir el vínculo entre los ciudadanos y el orden político dentro del Estado moderno.

La idea territorial y geométrica del espacio público, tan presente en la concepción del Estado soberano, supone que el ámbito político se define por unas actividades y movimientos que se desarrollan sobre una superficie bien delimitada y relativamente plana. La plaza ha constituido una de las imágenes más utilizadas para describir el foro político y la forma de encuentro entre ciudadanos. La idea de un ágora moderna, con extensiones inmensas, es empleada para describir una esfera pública en donde el ciudadano, los movimientos, los argumentos y las opiniones están a la vista de todos y de ninguno en particular. La plaza imaginaria de la esfera pública moderna presupone una idea territorial y geométrica de lo político.

Lo público entendido como plaza o esfera se nutre de ideas sobre espacios geométricos. El ágora situado en el centro de la polis griega bien delimitada por sus murallas es una imagen que ha sido persistente para concebir la esfera pública en el pensamiento político, mucho más allá de las particularidades del contexto de la Atenas de Pericles. En esa imagen de la plaza, los espacios públicos geométricos se encuentran en el exterior del ciudadano, donde todo el mundo puede ver y 
ser visto, donde los argumentos pueden ser expuestos con fuerza y controlados al mismo tiempo.

Esa concepción del espacio político es fundamental para las perspectivas de la democracia deliberativa, presentes en la teoría política contemporánea, que intentan definir una esfera pública en la cual prima la ilusión de transparencia, sinceridad, equidad y procedimiento, para controlar la contingencia de la vida política. ${ }^{5}$ Estos enfoques identifican la contingencia política como una de las principales fuentes de sinrazón e injusticia. La idea del espacio público deliberativo es geométrica, al pretender separar con una línea nítida el mundo interno del ciudadano de una esfera transparente exterior, en donde los asuntos políticos puedan estar a la vista de todos y de ninguno en particular. Para la democracia deliberativa, la opacidad del mundo interno del ciudadano quedaría iluminada con la ayuda de una razón más recta en una esfera pública transparente.

Lo que no se concibe en esas perspectivas es que el mundo interno no se rige necesariamente por leyes físicas ni es susceptible de un análisis basado en la observación visual. La contingencia del mundo interno no puede ser eliminada, puesto que la vida del ciudadano no se agota en un espacio público exterior y transparente, ni se define por una voluntad autónoma que desde su interior en cada momento le podría dominar y guiar, eliminando sus dudas, ordenando sus intenciones y reforzando su identidad.

La importancia de la contingencia de la que depende la relación entre el mundo interno del ciudadano y el orden político la enfatiza un pensador tan relacionado con el Estado soberano (en la teoría política y en las relaciones internacionales) como ha sido Thomas Hobbes. Cuando en Leviatán describe el poder soberano en términos de protección, orden y unidad, encontramos unas preocupaciones fundamentales acerca de la abstracción que supone siempre el vínculo entre los ciudadanos y el Estado. Para indagar en las posibilidades y

\footnotetext{
5 Para obras generales sobre la democracia deliberativa, ver, por ejemplo, Dryzek (2000) y Fishkin (2003).
} 
limitaciones de lo que Hobbes entiende como una necesaria abstracción del poder soberano, se detiene una y otra vez en los nexos entre el Estado omnicomprensivo y la vida contingente de los ciudadanos.

$\mathrm{Al}$ contrario de muchas interpretaciones convencionales de obras como Leviatán, cabe destacar que los problemas relacionados con la creación de un orden político estable no versan únicamente sobre unas formas y un contrato, que representarían una abstracción definitiva de las dimensiones contingentes de la vida política. El pensador de Malmesbury nos enseña, por el contrario, que la fundación del Estado no se elimina de una vez por la contingencia presente en la relación entre ciudadanos y orden político. Y una parte decisiva de esa relación, que Hobbes considera inherente a la res publica, es el mundo interno del ciudadano. Sin tener en consideración el mundo interno no podríamos apreciar la importancia que Hobbes asigna a facultades (o defectos) humanos como el temor, la soberbia, la memoria, el olvido, la imaginación y el juicio (Hobbes, 1996, caps. 13-15 y 29). La contingencia del mundo interno del ciudadano queda así estrechamente vinculada a entes políticos de dimensiones tan vastas como el Estado moderno (Hammar, 2008). En principio, ese mundo interno no es un espacio cerrado a los demás y a la esfera política, sino que es permeable al constituir una dimensión decisiva en la edificación del orden político como respuesta a aspectos presentes en el fuero interno del ciudadano, como son el temor, la soberbia y la inseguridad, que, en Leviatán, constituyen peligros constantes para el Estado (Hobbes, 1996, pp. 227-228).

Lo que Hobbes en Leviatán relaciona con el mundo interno no puede ser desplazado a una esfera estrictamente interior o privada, situada fuera de la res pública, sino que forma parte de espacios públicos internos. Estos lugares no casan con las figuras geométricas con las que se retratan las esferas políticas, según las cuales estar en dos lugares a la misma vez resulta imposible, porque contemplan la res publica en términos de la traslación de "cuerpos en el tiempo y en el espacio, categorías incontestadas por hallarse confirmadas a priori” (Roiz, 2003, p. 346; 2013, pp. 143-145). 
Las perspectivas políticas geométricas suponen además que "lo público siempre es externo al yo" (Roiz, 2003, p. 339). De ahí surge la idea de contemplar cualquier asunto relacionado con lo político como un objeto en la plaza, expuesto a la vista de todos y de ninguno en particular. La concepción de espacios públicos internos nos permite precisamente comprender cómo el ciudadano puede estar en varias esferas políticas a la vez y no quedar expuesto por completo en ninguna. Estar en dos lugares a la vez es algo que resulta inconcebible desde las perspectivas geométricas, al basarse estas en analogías sobre la presencia física de cuerpos en espacios estrictamente delimitados y mutuamente excluyentes (Elden, 2013, pp. 292-298). Dar por válido el punto de partida de que lo público se asemeje a un espacio geométrico, siempre situado en el exterior de los ciudadanos, ha llevado a la ciencia política a relacionar el mundo interno del ciudadano con privatización, psicologismo, subjetividad romántica o con un individualismo reducido a egoísmo racionalista.

Hobbes ve claramente la importancia política del mundo interno, pero al mismo tiempo pretende en Leviatán controlar esas dimensiones de lo público, para vedar tanto la contingencia que supone el mundo interno del ciudadano como atar firmemente su existencia al Estado soberano.

\section{Memoria, olvido y 'res publica'}

$\mathrm{Al}$ introducir el mundo interno en el estudio del Estado soberano, podemos apreciar la presencia del ciudadano en el espacio público y, lo que no es menos importante, la existencia de espacios públicos en el interior del ciudadano. La contingencia y permeabilidad del fuero interno indican que el ciudadano puede exteriorizar en el ágora únicamente partes y momentos de sus identidades, intereses e inquietudes, mientras que en su fuero interno se hallan fragmentos y tiempos paralelos que ejercen una influencia importante sobre su relación con la res publica. Ejemplos relevantes en ese sentido podemos observar en los procesos selectivos y contingentes de memoria y olvido, proyectados sobre entidades colectivas como el Estado soberano. 
Muchas nociones sobre la memoria (individual y colectiva) como elemento fundacional de la comunidad política son reveladoras, al indicar que los fueros internos se vinculan con la vida política, sin detenerse esas nociones en cómo tal nexo pueda producirse. Conviene por ello recordar que la memoria no es un registro exhaustivo de todo lo ocurrido en tiempos pasados, sino parte de procesos selectivos o discriminatorios, situados en sucesivos tiempos presentes, en los que también juegan un papel decisivo el olvido y la amnesia. El olvido puede constituir un mecanismo igual de importante que la memoria para la fundación de la comunidad política. El olvido de los sufrimientos e injusticias cometidas y experimentadas constituye un elemento decisivo para poner los cimientos de una entidad política (Loraux, 2009). Esa amnesia y mutus significa que la comunidad política o la nación dependen de que los ciudadanos hayan olvidado muchas cosas. ${ }^{6}$

La memoria y el olvido representan aspectos que indican que el mundo interno del ciudadano no queda confinado a un espacio estrictamente interior y vedado a los demás. La memoria y el olvido forman parte del individuo pero, al mismo tiempo, implican mucho más que fantasías solipsistas. En realidad entra y sale lo público constantemente en los procesos de olvido y memoria de los ciudadanos, formando parte de los juicios que realizan los ciudadanos constantemente en su fuero interno. Este tipo de procesos ponen de relieve la necesidad de reconsiderar la complejidad de los vínculos entre el ciudadano y la esfera pública.

Los procesos de memoria y olvido vinculan los fueros internos con la vida política. El movimiento de los recuerdos en el mundo interno, tan fundamentales para las personas y su self, no son fácilmente controlables, sino que pueden, por el contrario, aparecer y desaparecer sin control aparente. La contingencia de entrada y salida de ese mundo interno del ciudadano hace que estos procesos sean públicos y partes del fuero interno a la vez.

6 Sobre el mutus y el olvido en ese sentido, ver Roiz (2013, pp. 112-113). 
La memoria y el olvido como conceptos políticos señalan el nexo fragmentario, momentáneo y poroso entre exterior e interior del ciudadano. Indican que lo público no puede siempre ser fundado sobre la separación estricta y cuasigeométrica entre el interior y el exterior del ciudadano. El recuerdo de una persona o un suceso suele guardar una relación evidente con un mundo exterior, pero al mismo tiempo es imposible separar ese recuerdo de las facultades y contingencias del fuero interno del ciudadano que lo condicionan e, incluso, lo pueden hacer caer en el olvido.

La memoria y el olvido rescatan algunos puntos ciegos de la concepción geométrica de los espacios políticos que describen los movimientos entre lo público y lo privado en términos de separación estricta u ocupación total. La idea de una división tajante entre lo público y lo privado la podemos ver ejemplificada en perspectivas contractualistas que destacan los derechos públicos como garantes de la libertad privada del individuo. Otra cara de esa misma disyunción la encontramos cuando se afirma que lo público puede o debe ocupar totalmente lo privado, al sugerir que la intimidad de las personas también es pública o cuando las perspectivas marxistas declaman que el individuo privado ha de ser abolido para alcanzar la libertad. En el republicanismo, encontramos perspectivas que resaltan lo público como un espacio exterior a la vista de todos los ciudadanos y lo privado como un ámbito interior a la vista de cada uno y apartado de la acción política. ${ }^{7}$ Lo que comparten todos esos enfoques es una idea geométrica para describir la relación entre los ámbitos públicos y privados. Los objetos han de situarse dentro de uno u otro. La esfera pública debe y puede, desde esa perspectiva, librarse de las dimensiones del mundo interno que no le pertenece.

Podemos, por el contrario, partir de que la contingencia del mundo interno es inteligible y constituye un aspecto ineludible para entender la res publica. Esto implica que la pluralidad y la permeabilidad del self no son anecdóticas ni una mera disfunción en el ciudadano, que

\footnotetext{
Sobre la división entre el interior del individuo y el exterior político en el siglo XVI y XVII, ver Comparato (1996, pp. 149-170).
} 
pudieran ser eliminadas por una esfera pública más transparente, por una deliberación más ordenada, por una identidad más auténtica o por una razón más recta.

Interesarnos por el mundo interno en la concepción de lo político nos permite, por ejemplo, ver cómo en muchos contextos se define el ciudadano como un sujeto regido por el principio de identidad, al haber implantado ese "principio de la metafísica aristotélica in foro interno" (Roiz, 2008, p. 305). Podemos así entender cómo esa lógica está presente en ideas sobre el vínculo entre ciudadano y esfera pública, trátese de ciudadanos como portadores de derechos o deberes, como estrategas en constantes pugnas, como objetos determinados por una u otra pertenencia colectiva (sean esta clase, cultura, pueblo o nación, etc.) o como sujetos ciudadanos que deben seguir una evolución predeterminada para dominar su self y así alcanzar la integración plena en lo público. ${ }^{8}$ Convergen en esa visión perspectivas en principio tan dispares como la psicología evolutiva, el republicanismo moderno y la democracia deliberativa. Lo que comparten es el volver una y otra vez sobre la necesidad de formar y moldear el mundo interno de los ciudadanos siguiendo unas normas preestablecidas sobre, por ejemplo, la participación, la cohesión y la movilización constante. Se trata de un ciudadano entendido en términos de un agente que actúa en la esfera pública con la mente como motor ejecutor cargada de, por ejemplo, intenciones, prioridades, capacidades, lealtades y enemistades dadas. La mente de ese ciudadano constituye un poder centralizado y unitario que en cada momento pretende controlar las acciones exteriorizadas en la plaza de lo público.

Como consecuencia de la primacía de ese principio de identidad interna, la vida pública es concebida en términos dialécticos, según los cuales la contingencia in foro interno constituye complementos, adornos o disfunciones para la vida pública del ciudadano. La incertidumbre

\footnotetext{
8 Pierre Rosanvallon señala aspectos interesantes sobre la genealogía del ciudadano moderno en términos de representación y sufragio universal, con las repúblicas francesas como ejemplo histórico, pero la complejidad del fuero interno del ciudadano no aparece en su perspectiva (Rosanvallon, 1999, 2004).
} 
e inestabilidad con la que debe enfrentarse la política se hallan, desde esta óptica, en el exterior del ciudadano, lo cual exige eliminar o vedar la contingencia procedente del mundo interno. La ciudad, la plaza, el territorio, la muralla, el espacio, la esfera son términos que sitúan las fuerzas políticas en el exterior del ciudadano. A partir de esa exterioridad, los ciudadanos se relacionan públicamente, aspirando a que se desplace la contingencia del fuero interno a lo privado, a la intimidad, a la soledad, a lo personal, a la estética o a lo psicológico. Esa vida ciudadana se tiende a situar dentro de Estados soberanos, con los que se define lo público en términos geométricos, propios de las esferas, los territorios y los espacios estrictamente delimitados.

\section{Extensión y difusión del poder imperial}

A pesar de la pretendida exclusividad y universalidad del Estado soberano, es evidente que este ha coexistido con otros entes políticos durante muchos siglos. Los imperios modernos son sin duda uno de los poderes más importantes de esa coexistencia. El dominio del Estado soberano se establecía durante la misma época en la que se desarrollaban imperios de unas extensiones nunca vistas. La transformación experimentada por la cartografía hacía unos 500 años no solo coincidía con el surgimiento del Estado soberano, sino que también con esos poderes imperiales cuyas extensiones serían prácticamente inabarcables e indefinidas (Pagden, 1998; Yates, 1975).

El motor de la nueva cartografía política no solo era el trazar fronteras nítidas entre dominios estatales mutuamente excluyentes, sino que además se nutría de la navegación por mares abiertos y de expediciones en territorios desconocidos. Estamos ante la era de los descubrimientos y las conquistas, en la que el mundo político se convierte en globalidad. La mutabilidad y permeabilidad del dominio estatal no son, desde luego, cuestiones que surgen por primera vez en procesos de globalización hacia finales del siglo xx. La relación contingente entre el espacio político y el ciudadano es, por el contrario, algo que ha coexistido con el Estado moderno de forma constante. 
El imperio como objeto del saber político se remonta a la antigüedad clásica, y forma parte inherente del pensamiento occidental. A partir de la época helenística y con pensadores como, por ejemplo, Polibio, Livio, Cicerón y Séneca, el imperio formaría parte de temas recurrentes en la reflexión sobre una esfera política que no podía ser reducida a la polis clásica. ${ }^{9}$ Entre los significados atribuidos al imperio, encontramos justicia universal, poder sobre territorios extensos, civilización y orden mundial (Burbank \& Cooper, 2010; Doyle, 1986; Muldoon, 1999). Cuestiones que guardan una relación directa con la idea de imperio son la cosmópolis, la hospitalidad, el derecho natural, la migración e inclusión política, la intervención y la guerra justa (Cavallar, 2002; Pagden, 2003, pp. 171-199).

El imperio no es una forma de dominio político ajeno al mundo moderno y al Estado soberano. La concepción de dominio imperial implica mucho más que, por ejemplo, unas ideas anacrónicas sobre un translatio imperio medieval, cristiano, universal, que han sido utilizadas como contraste a la libertad republicana y el paso de la Edad Media a la Modernidad. ${ }^{10} \mathrm{El}$ imperio como concepto político no constituye un paréntesis histórico sin mayor trascendencia para el pensamiento moderno. Por el contrario, los problemas que suponen la expansión y difusión del poder político han estado presentes en el pensamiento moderno, tanto en la concepción del Estado soberano en Europa como en las empresas imperiales en las que se encontraban inmersas varias de esas entidades soberanas emergentes. Resulta por ello cuando menos curioso que el imperio no ocupe un lugar más destacado en la teoría política contemporánea.

La expansión de los imperios modernos ha sido estudiada extensivamente, sobre todo desde perspectivas históricas. A pesar de ello,

\footnotetext{
9 Ver, por ejemplo, Tabachnik y Koivukoski (2009), Erskine (1990), Meiggs (1972) y Schoefield (1991).

10 Sobre el concepto medieval de translatio imperio como una monarquía cristiana universal con legitimidad divina que contrasta con la libertad republicana moderna, ver Pocock (1975). Para una crítica de esa interpretación del pensamiento de Marsilio de Padua y de la separación estricta entre el dominio imperial y la libertad republicana, ver Nederman (2009, pp. 177-189).
} 
en la teoría política contemporánea suele constituir un punto ciego el hecho de que el movimiento con el que el Estado moderno iba cubriendo el mundo iba acompañado por expansiones imperiales, cuyo dominio político difería sustancialmente del poder soberano vinculado con ese Estado. Al contrario de la soberanía estatal definida por espacios mutuamente excluyentes y fronteras nítidas, los imperios se caracterizaban tanto por la extensión como por la difusión del poder y del espacio político.

Es importante señalar que los principios y las aspiraciones de la soberanía estatal no son necesariamente antagónicos a los de un dominio imperial, a pesar de haber sido definidos en términos opuestos por muchas versiones del republicanismo moderno (Andrew, 2011; Hankins, 2010; Nelson, 2010). La relación entre Estado (o república) e imperio con frecuencia se ha caracterizado por solapamiento, lo cual podemos observar en la dependencia mutua entre ambos conceptos al describir el poder, la libertad y la expansión de la república romana. Este vínculo entre libertad republicana romana y poder imperial también lo encontramos en pensadores como Maquiavelo (Balot, 2010; Hörnqvist, 2004; Springborg, 1992, pp. 181 y ss.).

La relación entre Estado moderno e imperio es problemática, en parte debido a que el dominio político de los imperios modernos se enfrentaba a problemas que iban mucho más allá de los principios geométricos relacionados con el Estado soberano. Para los imperios, el territorio y las fronteras no constituyen un espacio dado que delimita la vida política y el gobernar. El espacio político de un imperio representa, por el contrario, apertura y movimientos de extensión y difusión. Esto significa, entre otras cosas, que el vínculo entre ciudadanos (o súbditos) y orden político no puede ser establecido aplicando los principios de espacios geométricos del Estado soberano. En el imperio, no existen límites nítidos que de antemano delimiten la inclusión o apropiación de los ciudadanos o súbditos. La noción de lo público como un espacio estrictamente intraterritorial no es aplicable al imperio, al ser precisamente la mutabilidad de su extensión y la variabilidad de pertenencia a él unas de las características del dominio imperial. 
La soberanía ha sido un concepto importante para los imperios, pero no como un hecho consumado o un principio exclusivo para el ejercicio del poder, sino como una aspiración a controlar cuanto se pueda o se permita en un mundo político contingente. El ejercicio del poder imperial es desigual y se adapta a unas circunstancias que, dada la extensión y expansión (y contracción) del imperio, son difícilmente previsibles. El control exhaustivo sobre un territorio delimitado podía en algunos momentos y lugares ser factible para un imperio, mientras que en otros no se consideraba ni deseable. Del mismo modo podría, en algunos contextos, considerarse urgente definir la pertenencia y el estatus legal de los habitantes de los territorios conquistados, mientras que en otros esas definiciones no fueron objeto de mayor atención por el poder imperial (Benton, 2010, pp. 3-4).

Al poner nuevas zonas y habitantes bajo su poder, el imperio también se topaba con personas que salían y entraban en un espacio político caracterizado por permeabilidad, movilidad y lejanía. El control y la jurisdicción sobre las personas no podían ser ejercidos con la ayuda de los territorios, la cercanía y el mapa. En ausencia de un control soberano sobre el espacio político y los ciudadanos, la lealtad y la traición, tanto de los súbditos o contratados enviados a zonas lejanas como de la población local de estas, constituían preocupaciones constantes para el poder imperial (Benton, 2010, cap. 2).

La posibilidad de cometer un delito de traición únicamente era posible si una persona pertenecía al dominio imperial, al mismo tiempo que la traición con frecuencia se definía como el acto de situarse fuera de esa pertenencia (Benton, 2010, p. 101). Este dilema indica la porosidad del espacio político y la mutabilidad de la pertenencia política en los imperios modernos. El dominio imperial se proyecta sobre posesiones territoriales y de súbditos o ciudadanos, pero al mismo tiempo depende de personas y fronteras que se caracterizan por mutabilidad y porosidad. Aspectos como la pertenencia, la posesión, la lealtad y la traición no solo se remiten a una esfera pública, un estatus legal o un territorio en el exterior del ciudadano, sino que también vinculan su mundo interno con el orden político. Al contrario de lo que pretende el Estado, el poder imperial no puede proyectar 
esos nexos sobre una ciudadanía y territorio delimitados y estáticos, controlados por una voluntad soberana.

Los imperios modernos ya no existen como entidades políticas institucionalizadas. Tampoco hay Estados contemporáneos que puedan ser definidos como imperios. A pesar de ello, el imperio como concepto político es importante, porque señala la complejidad de gobernar un mundo cambiable que no puede ser reducido a espacios geométricos, sean estos descritos como territorios delimitados, control soberano o esferas públicas. Los dilemas de legitimidad, pertenencia, identidad y ciudadanía no podían ser resueltos de forma geométrica por el poder imperial, sino que formaban parte de gobernar las contingencias inherentes a un dominio extenso y difuso. No debemos olvidar que ese dominio coexistía de forma íntima con el Estado soberano, y muchos de los problemas de difusión y extensión del poder político con los que se enfrentaban constantemente los imperios han sido heredados - pero no resueltos- por ese Estado.

\section{Referencias}

Andrew, E. G. (2011). Imperial republics. Revolution, war, and territorial expansion from the English Civil War to the French Revolution. Toronto: University of Toronto Press.

Armitage, D. (2013). Foundations of modern international thought. Cambridge: Cambridge University Press.

Balot, R. (2010). Polybius advice to the imperial republic. Political Theory, 38(4), 483-509.

Bartelson, J. (2009). Visions of world community. Cambridge: Cambridge University Press.

Benton, L. (2010). A search for sovereignty. Law and geography in European empires, 1400-1900. Cambridge: Cambridge University Press.

Boucher, D. (2009). The limits of ethics in international relations. Oxford: Oxford University Press.

Burbank, J., \& Cooper, F. (2010). Empires in world history. Powver and the politics of difference. Princeton: Princeton University Press.

Cavallar, G. (2002). The rights of strangers: theories of international hospitality, the global community, and political justice since Vitoria. Aldershot: Ashgate. 
Comparato, V. I. (1996). A case of modern individualism: politics and the uneasiness of intelectuals in the Baroque Age. En J. Coleman (Ed.), The individual in political theory and practice (pp. 149-170). Oxford: Clarendon.

Doyle, M. W. (1986). Empires. Ithaca: Cornell University Press.

Dryzek, J. (2000). Deliberative democracy and beyond. Oxford: Oxford University Press.

Elden, S. (2013). The birth of territory. Chicago: University of Chicago Press.

Erskine, A. (1990). The Hellenistic Stoa: political thought and action. Ithaca: Cornell University Press.

Fishkin, J. S., \& Laslett, P. (Comps.). (2003). Debating deliberative democracy. Oxford: Blackwell.

Hammar, B. (2001). Interiores y exteriores politológicos. Foro Interno: Anuario de Teoría Política, (1), 75-113.

Hammar, B. (2008). Metonimias del Estado soberano. Utopia y Praxis Latinoamericana. Revista Internacional de Filosofía Iberoamericana y Teoría Social, 13(43), 33-48.

Hankins, J. (2010). Exclusivist republicanism and the non-monarchical republic. Political Theory, 38(4), 452-482.

Hobbes, T. (1996). Leviathan, or the matter, form, \& power of a commonwealth. Cambridge: Cambridge University Press.

Hörnqvist, M. (2004). Machiavelli and empire. Cambridge: Cambridge University Press.

Laxton, P. (Comp.). (2001). The new nature of maps. Essays in the history of cartography. Baltimore: Johns Hopkins University Press.

Loraux, N. (2009). La ciudad dividida. El olvido en la memoria de Atenas. Buenos Aires: Katz.

Meiggs, R. (1972). Athenian Empire. Oxford: Oxford University Press.

Muldoon, J. (1999). Empire and order. The concept of empire 800-1800. Londres: MacMillan.

Nederman, C. J. (2009). Lineages of European political thought. Explorations along the medievall modern divide from John of Salisbury to Hegel. Washington: The Catholic University of America Press.

Nelson, E. (2010). The Hebrew republic. Jewish sources and the transformation of European political thought. Cambridge: Harvard University Press.

Olsson, G. (2007). Abysmal. A critique of cartographic reason. Chicago: University of Chicago Press. 
Pagden, A. (1998). Lords of all the world. Ideologies of empire in Spain, Britain and France c. 1500-c. 1800. New Haven: Yale University Press.

Pagden, A. (2003). Human rights, natural rights, and Europe's imperial legacy. Political Theory, 31(2), 171-199.

Pocock, J. G. (1975). The Machiavellian moment. Florentine political thought and the Atlantic tradition. Princeton: Princeton University Press.

Roiz, J. (2003). La recuperación del buen juicio. Teoría politica en el siglo veinte. Madrid: Foro Interno.

Roiz, J. (2008). Sociedad vigilante y mundo judio en la concepción del Estado. Madrid: Editorial Complutense.

Roiz, J. (2013). El mundo interno y la política. Madrid: Plaza y Valdés.

Rosanvallon, P. (1999). La consagración del ciudadano. México D.F.: Instituto Mora.

Rosanvallon, P. (2004). Elpueblo inalcanzable. Historia de la representación política en Francia. México D.F.: Instituto Mora.

Schoefield, M. (1991). The stoic idea of the city. Cambridge: Cambridge University Press.

Serrano Marín, V. (2010). Soñando monstruos. Terror y delirio en la modernidad. Madrid: Plaza y Valdés.

Springborg, P. (1992). Western republicanism and the Oriental Prince. Cambridge: Polity Press.

Tabachnik, D. E., \& Koivukoski, T. (Eds.). (2009). Enduring empire, ancient lessons for global politics. University of Toronto Press.

Yates, F. A. (1975). Astraea. The imperial theme in the sixteenth century. Londres: Routledge. 
